\title{
On Promotion of Teaching Through Scientific Research in Colleges and Universities
}

\author{
Fang Liu \\ Xijing University, Xi'an, Shaanxi, China \\ 397399097@qq.com
}

Keywords: Scientific Research, Teaching, Promotion

\begin{abstract}
Teaching and scientific research are the two main ways of training higher education personnel. This is also an important feature of higher education different from other levels of education. Teaching as the main responsibility of colleges and universities directly influences the recognition of students in society and the reputation of the school. At the same time, the innovation of knowledge through scientific research is another important function of the university. It is an important measure of the level of a university's education and its social contribution. Scientific research requires high-level talents, and its source is based on good teaching. It is not enough to improve the quality of teaching. It is necessary to understand the latest developments in scientific development and have Scientific way of thinking, so scientific research and teaching promote each other.
\end{abstract}

\section{Connotation of Scientific Research Promoting Teaching}

\subsection{To rich teaching content}

Teachers can introduce scientific research projects, research papers, and scientific research methods into teaching content, promote the updating and reform of teaching content to enrich and correct teaching content.[1] They can form a high level of theory, substantial content, practicality, distinctive features, and Self-aware, fledged classroom teaching system. In view of the strong theoretical and practical characteristics of chemistry curriculum teaching, taking the actual cases in its own scientific research as the content, when teaching related courses, the explanation is more flexible and vivid, and it is easy for students to understand and accept. For example, in teaching "International Trade", when I talked about J.H.Dunning's The Eclectic theory of International Production in the theory of international trade, I introduced it into The academic paper "International Trade Issues" published in the "OIL model to see the strategic adjustment of large multinational corporations investing in China and Chinese countermeasures", so that students understand the essence of the OIL model and its practical application; when speaking about international trade barriers, the research paper "foreign trade of China encounters technical barriers and the countermeasures" have been introduced into teaching. When speaking of the opportunities and challenges brought by China's accession to the WTO, the paper "Intruded into WTO and Chinese petrochemical industry has been introduced into teaching. The development strategy of the industry enables students to intuitively understand the international trade knowledge, to abstract the theoretical knowledge, and apply the theory to practice.

\subsection{To promote the reform of teaching methods}

In recent years, the Colleges and Universities encourages teachers to explore the reform of teaching methods . and teachers take it as their research object. Not only have they achieved fruitful results in scientific research, but also actively applied them into practice to promote teaching methods Reform and innovation. I conducted the "International Trade Multimedia Courseware Development", "International Economic Cooperation Course Construction and Teaching Reform", and "International Trade Electronic Commerce Teaching Experimental Construction". The teaching reform results have been put into practice in teaching, and which effect is remarkable. In teaching, students are encouraged to discuss hot topics. At the end of the course, in order to consolidate and apply the 
theoretical knowledge learned, students are guided to write an essay, and prepare for each topic. The group made speeches and commented on the teachers. Through these teaching activities, students' ability of solving problems and working in a coordinated manner improved, but also their verbal communication skills enhanced their self-confidence. It is crucial for students to embark on a job in the future.

\subsection{To improve the level of teachers}

Scientific research is an important way to improve the quality of teachers and enhance their knowledge. Social development is endless, and scientific development is endless[2]. Especially in today's information age, the development of technology is changing with passing days. Only through scientific research can teachers master the development trends and trends of the discipline in time, accurately understand and grasp the characteristics of the discipline, and research Methods and links with other disciplines, improve the knowledge structure, update the knowledge system, and improve the academic level. Only by actively engaging in scientific research can we have the desire and motivation to acquire new knowledge through various channels. Only when teachers have profound knowledge can we enhance our understanding of the content of the lectures and the ability to integrate them; Through the teaching of scientific viewpoints and methods, students' thinking ability can be cultivated and students' horizons can be expanded to obtain better teaching effects. When teachers gradually enrich the frontier of the subject area into the teaching content, they may form new ones .

The scientific system has become a valuable source of cultivating students' innovative ability. At the same time, teachers in the classroom will use the research methods and means of scientific research to show students through teaching, which can stimulate students' interest in learning. Historical experience at home and abroad has proven that a university without a high-quality scientific research cannot establish a high-quality teaching staff. It is also impossible to have a high level of education quality and scientific research without a high-quality teaching staff. Through scientific research, teachers can profoundly understand the social requirements for cultivating talents and understand the social talent market's requirements for talent cultivation and entrepreneurship. Only in this way can teachers fully grasp the academic dynamics at home and abroad, and accurately understand the status and logical connections within the curriculum that the courses they teach in the entire discipline. The new knowledge gained in scientific research and new achievements in science and technology are reflected in teaching in a timely manner so as to improve the teaching and academic level of teachers.

\subsection{To improve teaching quality}

By participating in scientific research activities, teachers can broaden their horizons and become familiar with the development of disciplines. In teaching, they can promote the reform of teaching content and curriculum system, and create diverse and personalized teaching methods. New knowledge, new technologies, new processes, and new methods are added to the curriculum content in a timely manner to compile textbooks that can fully reflect the advantages and characteristics of the subject, have distinctive features, and play a key role in improving teaching quality.

\section{The core of Scientific research promote teaching --- experimental innovation}

\subsection{To improve the level of teaching with comprehensive experiments}

Experiments are the combination of skills and knowledge. Students verify the theoretical knowledge of books through experiments. At the same time, through the analysis of experimental processes and phenomena, the knowledge can be extended. After the basic experiment is over, exploratory experiments are added and experiments are conducted.

The basic procedures for implementation are basically the same as the scientific research process. It can inspire students to initially grasp the basic ideas and methods of scientific research, develop students' ability of self-learning, ability of comprehensive analysis, collection and processing of information capabilities, independent hands-on ability, solidarity and cooperation, and 
scientific creation. Thinking ability[3]; At the same time, the ability of experimental report writing is gradually transferred to the writing of scientific research papers, the depth of the paper's format requirements, data query, data analysis and other aspects, so that students have a systematic understanding of the discipline. Therefore, the key to improving the level of scientific research to promote teaching is the experimental innovation with comprehensive experimental skills.

\subsection{To promote teaching by forthputting provincial and ministerial key laboratories}

The key laboratories have gathered first-rate professionals, possessed first-class scientific research results, and first-rate professional experimental equipment, and the cooperation and exchanges at home and abroad were frequent. Although the main research direction of key laboratories is relatively stable, with the development of similar international disciplines, the changes in research projects, the direction of research often needs to be properly adjusted, and the content of experimental research is less repetitive and faster. Innovation research, especially source innovation research, is the core of survival and development of key laboratories[4]. The long-term out-of-focus of key laboratories and teaching has made students lack effective communication with the key laboratories of their faculties, and knows very little about the experts and research fields working in key laboratories. Through the opening of key laboratories to undergraduates, undergraduates use equipment from key laboratories to complete dissertations under the guidance of their instructors. Students can initially understand the frontiers of related disciplines and the process of curriculum application, demonstration, project establishment and experimental research. Awareness of research and innovation was cultivated and the level of graduation thesis was improved. At the same time, the key laboratories have participated in teaching and their resources have been mined and utilized to the maximum extent, which has played a role that basic and specialized teaching laboratories cannot match; at the same time, it has also changed that the curriculum learning and scientific research practices are actually out of line with the actual engineering. Therefore, it's important for key laboratories in supporting experimental innovation.

\section{Problems Urgently Needed to Solve in Scientific Research promoting Teaching}

Scientific research has played an important role in promoting teaching, but there are significant differences between scientific research and teaching. Reasonably solving the contradiction between teaching and research is an urgent problem to be solved.

\subsection{To solve the problem of mutual separation between scientific research and teaching}

In the current practice of teaching in our university, the teachers with lower professional titles are lack of project funding; To increase the income they have to struggle in teaching. Contrary to this, high-professional teachers are mainly engaged in research work and undertake fewer teaching tasks, so scientific research and teaching are divided, which making teachers mostly unable to realize the practical significance and value of scientific research in improving teaching quality.

\subsection{Conflict between teaching arrangements and scientific research}

Teaching is a highly planned work and must be conducted in strict accordance with the teaching plan.[5] However, in the scientific research work, due to the time and season requirements of some research projects are particularly strong, which led to the conflict between teaching and scientific research. It is also a problem that must be solved.

\subsection{The young teachers' scientific research initiation and training}

The cultivation of young teachers is the foundation of university's development. However, due to young teachers are congenitally insufficient in competing for various projects, the young teachers' scientific research ability is weak, which is not conducive to the improvement of teaching. The leader of university should appropriately reduce their teaching task and encourage them to engage in scientific research.

\subsection{The positioning of teaching research}

Teaching research is an important aspect of scientific research, but teaching research is different from general scientific research projects; scientific research is a problem that solves problems in 
production and understanding of the objective world; it has the characteristics of wide adaptability; scientific research must focus on solving the problem. Teaching is to solve practical problems. The purpose of teaching and research is to bridge the gap between teaching theory and practice, and transform advanced teaching theories into explicit teaching behavior.

\subsection{Problems in the application of teaching reform achievements}

The results of teaching and research are directly serving the teaching. However, in teaching, the application of the teaching reform achievements only shows in terms of papers and awards, It is also a problem that how to use the achievements of teaching reform in teaching practice.

\section{References}

[1] Shi Hui. Reflections on Scientific Research Promoting Undergraduate Teaching[J]. Shaanxi Normal University, 2015, (2):45-48.

[2] Zhang Lingyu. Knowledge and Practice of Scientific Research Promoting Undergraduate Teaching[J]. Chinese Culture Forum, 2017, (8): 68-70.

[3] Cheng Xiaosu, Research Universities Promote Research Reflections on Entering Undergraduate Teaching[J]. Polytechnic Higher Education Research, 2015, (6): 74-78.

[4] Wei Fengrong. The combination of scientific research and teaching is the fundamental way to cultivate talents[J]. Journal of the Central University for Nationalities, 2016, (2): 179 - 181.

[5] Wei Hua. Promoting Experiment Teaching Reform with Scientific Research and Cultivating Students' Innovative Spirit and Practical Ability[J]. Chinese University Teaching, 2016, (3): 81-83. 